\title{
Discursos sobre la viña y el vino: nuevos territorios en el imaginario social'
}

\author{
Enrique Aliste², Beatriz Bustos 3 , Daniella Gac ${ }^{4}$ \\ y Raphael Schirmer ${ }^{5}$
}

\begin{abstract}
RESUMEN
La industria vitivinícola en Chile es uno de los sectores exportadores más dinámicos de los últimos 30 años, lo que ha implicado profundas transformaciones en los territorios donde se ha instalado. Este artículo examina los discursos de este sector, para identificar el rol que juega el paisaje y los territorios del vino en su comercialización. A partir de los conceptos de Bourdieu sobre campos sociales y exclusión social, y evidencia empírica obtenida de las páginas web de viñas del Valle Central, el artículo identifica cinco elementos predominantes: tradición, vínculo europeo, terroir, medio ambiente y exclusividad. Se concluye que el concepto de terroir empleado, si bien refiere a las ideas francesas de producción vitivinícola, excluye a los trabajadores y habitantes de los territorios del vino, por lo que es un concepto más bien intencionado hacia los mercados de destino que un concepto con contenido de identidad local y territorial, distanciándose de las condiciones locales.
\end{abstract}

Palabras clave: Valle Central, viñas, representaciones, exclusión social, imaginarios.

\begin{abstract}
The Chilean wine industry has become one of the most dynamic exporting sectors over the last 30 years, pushing deep transformations in the territories where it is established. The paper examines the current imaginaries and discourses prevailing in the Chilean wine industry, in order to identify the role that the landscape and the wine territories play in its commercialization. Departing from Bourdieu ideas of social space and social exclusion, and from empirical evidence obtained through the analysis of official websites of wineries of the Chilean Central Valley, the article identifies five predominant elements in these discourses: tradition, European connection, terroir, environment, and exclusivity. The paper concludes that although the concept of terroir used in the websites relates to French ideas, it excludes workers and inhabitants from the wine territories, thus, it becomes a concept targeting exporting markets, as opposed to a concept with local and territorial identity. As such, the imagined territory distance itself from the local conditions.
\end{abstract}

Keywords: Chilean Central Valley, vineyards, representations, social exclusion, imaginary.

Artículo elaborado gracias al apoyo del proyecto ECOS-CONICYT C11HO3 "Los paisajes del viñedo chileno: entre arraigo, integración de nuevos modelos y discursos sobre la viña y el vino". Artículo recibido el 18 de agosto de 2017, aceptado el 20 de diciembre de 2017 y corregido el 15 de junio de 2018

Departamento de Geografía, Universidad de Chile (Chile). E-mail: ealiste@uchilefau.cl

Departamento de Geografía, Universidad de Chile (Chile).E-mail: bibustos@uchilefau.cl

Centro de Estudios del Desarrollo Regional y Políticas Públicas (CEDER), Universidad de Los Lagos (Chile). E-mail: daniella.gac@ulagos.cl

Laboratoire PASSAGES (UMR5319), Université Bordeaux Montaigne (Francia). E-mail: Raphael.Schirmer@u-bordeaux-montaigne.fr 
Chile cuenta en la actualidad con 12 Regiones vitívinícolas, que comprenden desde la Región de Arica - Parinacota hasta la Región de los Lagos, las cuales alcanzan en total 137 mil hectáreas plantadas de viñedos (SAG, 2016). La variedad geográfica varía desde valles con apenas 2,10 hectáreas (Tarapacá) a otros que sobrepasan las 52 mil hectáreas (Maule). De acuerdo a estadísticas recientes, el año 2017 tuvo un balance positivo para la exportación de vino embotellado alcanzando los MM US\$1.604, que significó un aumento del 3\% del volumen respecto del año 2016 (Buzze$\mathrm{tti}$, 2018). Este contexto da cuenta de una industria estable en las dinámicas de posicionamiento de sus productos en los mercados extranjeros. En cuanto a exportaciones de vino embotellado, este ha alcanzado un récord en los últimos cinco años con $451 \mathrm{MM}$ litros. Los buenos resultados obtenidos por esta industria desde el año 2014 han consolidado a Chile como el cuarto país exportador de vinos más importante del mundo (Vinos de Chile, 2016).

Si consideramos además que la industria admite emplear (directa o indirectamente) a cerca de 100 mil trabajadores (Vinos de Chile, 2014) y se producen alrededor de 1.075 millones de litros de vino, se puede dimensionar la relevancia que esta actividad tiene tanto en la economía como en los territorios donde se desarrolla (Mondrego, 2011; Gac, 2017). A ello se suma su relevancia cultural, dado que el vino formaría parte de los elementos clásicos que distinguen aquello que comúnmente se denomina la identidad chilena (Bravo Núñez, 2008; Lacoste, 2005; Larraín, 2001).

Con una cifra que sobrepasan las 11.697 propiedades con plantaciones de vides para vinificación y 339 bodegas a nivel nacional (INE, 2011), la industria vitivinícola puede ser definida como una industria concentrada, puesto que solo cuatro grupos económicos asociados a viñas más grandes de Chile (Concha y Toro, San Pedro Tarapacá, Santa Rita y Santa Carolina) representan el 33\% del valor de las exportaciones de vino del país (Visser \& Langen, 2006).

En términos de consumo, el año 2009 Chile consumió alrededor de 250 millones de litros, y su evolución per cápita ha tenido un crecimiento sostenido, de 12,5 litros año/por persona el año 2000 a 14 litros el 2016 (Vinos de Chile, 2016), muy lejos de los valores de consumo de Francia (38,2 litros per cápita el 2013) y Argentina (23 litros per cápita 2013) (OIV, 2014). Sin embargo, a diferencia de estos países, la tendencia de la última década es al crecimiento, lo que ha transformado a Chile en un mercado pequeño pero atractivo para los productores mundiales.

Es por ello que el capital internacional también ha tenido y tiene un rol destacado en el desarrollo de la industria vinícola en Chile. En una primera etapa a través de la llegada de Miguel Torres a fines de los '70, la cual fue seguido, en una segunda etapa, por capitales franceses como Barón P. de Rotschild o norteamericanos como Mondavi, a principios de la década de 1990, quienes se han concentrado en el nicho de los vinos de alta gama para el mercado de exportación. Es en este momento que se inicia un nuevo ciclo de la industria del vino chileno, de orientación exportadora, que aprovechó una serie de oportunidades para insertarse en los mercados europeos durante la década de 1980; por una parte, las políticas anti-alcoholismo europeas que privilegiaron el vino por sobre los destilados, mientras que las políticas antiapartheid hacen desaparecer a Sudáfrica como proveedor de vinos, particularmente Inglaterra, transformándose en un destino interesante para el vino chileno. Desde la perspectiva nacional, las políticas de liberalización comercial impulsadas durante la dictadura atraen a inversionistas extranjeros y el vino se convierte en un negocio rentable.

De acuerdo a Vergara (2001) cerca del 70\% de la Inversión Extranjera Directa (IED) que llegó al rubro vinícola chileno proviene de capitales franceses, seguido con un $30 \%$ por capitales nortea- 
mericanos, con alguna participación de capitales españoles y australianos. Uno de los efectos de la llegada de capitales extranjeros y la apertura al comercio exterior es un cambio en los actores de la industria del vino (Vergara, 2001), que, de ser principalmente agricultores, pasan a ser inversionistas y empresarios, los que asumen este rubro como un negocio paralelo (o en algunos casos un pasatiempos) a sus principales áreas de negocio. Dada las características que tiene este rubro en relación al prestigio (tener una cava personal para reuniones de negocios, regalar a personas importantes, etc.) y ser asociado a un tradición y experiencia. En definitiva, un asunto de posición y distinción (Bourdieu, 1988).

Este cambio tiene significado para los modelos de negocio asociados al vino. Según antecedentes recopilados, es posible identificar 4 áreas de negocios principales asociados a la industria del vino en Chile: (1) producción de uva vinífera, (2) el proceso mismo de vinificación, (3) el negocio inmobiliario, más asociado a la especulación financiera de las tierras, y (4) la comercialización y marketing del vino en mercados de exportación, donde se produce la real ganancia de la vitivinicultura, ya que lo importante es el acceso a los mercados y puntos de venta.

Por ello es que el auge de la actividad vitivinícola ha impactado fuertemente los territorios del Valle Central de Chile ${ }^{6}$. Grandes inversiones, numerosos terrenos convertidos en viñedos, antiguas zonas con bajo valor agrícola, etc., han agregado valor a una actividad que goza de reputación y cada día más adeptos en el mundo y en Chile. Este, como otros sectores, han gozado de una "conversión productiva de las regiones hacia aquellos sectores que aprovecharan sus ventajas comparativas, e incentivando de modo claro el desarrollo tecnológico que acelerase procesos productivos basados en recursos naturales" (Bustos, 2012, p. 220). Ejemplos de este tipo de territorios son principalmente los del salmón en la región de Los Lagos, los forestales en la zona centro sur, especialmente las regiones del Maule, Bio-Bío, La Araucanía y Los Ríos, y, por cierto, los del vino en el Valle del Central, expandiéndose paulatinamente hacia el norte y sur a la conquista de nuevos territorios con virtudes para distintas cepas y cosechas, contribuyendo a la producción de nuevos paisajes del vino (Asselot, 2003). En general, se trata de territorios que se han concebido como proveedores de commodities basados en la provisión de recursos naturales al sector productivo, que en el caso del vino adquieren una connotación particular, definiendo a este sector como proveedor de tanto de specialities (vinos de calidad), como de commodities (vinos varietales, vinos a granel o mosto) (Chazarreta, 2013).

La emergencia de una concepción de sociedad mediada por el "espíritu de la empresa" (Castel, 1997: 32), se ha visto tensionada por este orden espacial, económico y social, que marca una de las rupturas más relevantes de la desmodernización (Touraine, 1997), definida también como las consecuencias perversas o no previstas de la modernidad (Giddens, 1993; Beriain, 1996; Robles, 2000), la que se caracteriza por la "disociación de los dos universos, el de las técnicas y los mercados y el de las culturas, el de la razón instrumental y el de la memoria colectiva, el de los signos y el del sentido" (Touraine, 1997, p. 33).

Al mismo tiempo, se materializa un importante proceso de transformación espacial de orden material, que se puede verificar en los cambios concretos en la estructura de la propiedad, de

Macro zona productiva definida por la Corporación de Fomento de la Producción (CORFO) en el año 1950, y que se extiende desde la Región de Valparaíso a la Región del Bío Bío. 
las superficies de cultivo, de las superficies regadas, entre otras (ODEPA, 2015), y de un proceso menos evidente y más silencioso que dice relación con la dimensión imaginaria de las transformaciones en un territorio (Aliste \& Musset, 2014) del cual se observa, a través del producto que se elabora, elementos virtuosos relacionados a la imagen de marca, tradición, historia y patrimonio que se proyecta en la producción de vinos en Chile y a ciertos atributos cuyo sello se busca en las virtudes de un determinado territorio.

Como una forma de explorar estos imaginarios, este trabajo se ha propuesto identificar las principales dimensiones que este sector asume respecto de una identidad configurada en torno a la producción de vinos y a la forma en que las bodegas se posicionan frente a esta condición. Para ello, conceptos como paisaje, terroir, exclusividad y exclusión son problematizados con el propósito de indagar en torno a esta nueva geografía social de las viñas y el vino, recurriendo también a nociones como mundo del vino ${ }^{7}$ y territorios del vino ${ }^{8}$.

Para responder a estos objetivos se ha optado por un acercamiento metodológico de tipo cualitativo, estableciendo como unidad de análisis las páginas web de las bodegas catastradas por la Corporación Chilena del Vino (2010), instaladas en el Valle Central9, muestra que comprendió un total del 41 bodegas $^{10}$.

El enfoque metodológico utilizado, es el análisis de contenido, puesto que orienta la mirada hacia la comprensión de los aspectos tanto discursivos como simbólicos (Krippendorf, 1990; Tijoux, 2013). La selección de este enfoque plantea el desafío de considerar cada uno de los elementos y a su vez la interacción que éstos establecen"1 a través de la codificación inductiva de las variables de interés, lo que permite la descripción y análisis para la discusión de los alcances.

De este modo, se propone interrogar a la industria del vino desde la aproximación comprensiva de sus páginas web, abordando sus contenidos como símbolos que permiten el acercamiento de la realidad social y territorial, centrando la mirada no solo en los aspectos descriptivos o visibles (como lo son las unidades lingüísticas o las imágenes del texto), sino también a los aspectos que construyen el contexto donde se posiciona la información, definido como el medio empírico o marco de referencia para este tipo de abordaje metodológico (Krippendorf, 1990).

\footnotetext{
La denominación "mundo del vino", se entiende aquí como un dominio semántico referido a los diversos significados que se construyen implícitamente como producto de un imaginario social. Actúan aquí dispositivos de representación social que se acompañan de una serie de significados no declarados, pero que movilizan ideas en torno a lo que representa el medio que gira en torno al vino: buen gusto, placer, refinamiento, elegancia, al mismo tiempo que viñedos ordenados y organizados, arquitectura moderna en los viñedos y bodegas (Blanco et al., 2003; Cruz et al., 2003; Sáez et al., 2003; Curard, 2003), cepas, tecnología, etc.

8 La denominación "territorio del vino", se entiende acá como una derivada de la noción de territorio en el sentido que plantea Di Méo (1998), esto es, como una apropiación y producción ideológica, simbólica y material del espacio geográfico.

9 Se seleccionaron las bodegas del Valle del Valle Central, puesto que éste es considerado uno de los Valles de consolidación de la industria vitivinícola de exportación, además por ser el sector de mayor tradición en la producción de vinos de Chile y encontrarse instalados los vinos con mayor tradición dentro y fuera del país (Del Pozo, 2004: Bengoa, 2012)

10 Se adjunta el detalle de las bodedas en el anexo al final de este trabajo.

1 Krippendorf distingue a las unidades de análisis en tres tipos: las unidades de muestreo, definiéndolas como las unidades materiales del estudio; las unidades de registro, identificándolas como los contenidos a analizar que se encuentran contenidas en las unidades de muestreo, el cual es la parte categorizada y comparable de la unidad de análisis; y, finalmente, las unidades de contexto, el cual consiste en la información proporcionada por el contexto que es posible identificar la unidad de muestro seleccionada (Krippendorff, 1990: 81).
} 
Lo que podemos apreciar a partir de la discusión conceptual, es que la noción de discurso tiene un peso, o bien, una responsabilidad asumida para explorar la dimensión analítica de este trabajo. Y en este sentido, cabe entender el discurso en su sentido foucaultiano, en tanto práctica que articula poder, saber y verdad (Foucault, 1971). De esta forma, referirse a prácticas discursivas debe entenderse como el procedimiento bajo el cual se va estableciendo un modo particular de entender y darle forma a un contexto que interesa explorar.

A partir de estos antecedentes recopilados, se discute la existencia de un proceso de exclusión social de carácter espacial, que actúa en el nivel del imaginario especialmente a partir del criterio de ausencia o invisibilización (Foucault, 2002). De esta forma, se explora el papel que juegan conceptos de carácter socio-espacial como paisaje, terroir y territorio, y de qué modo estos conceptos son modelados a partir del imaginario social movilizado por estas nuevas formas de exclusión.

\section{Lo socio-espacial en las prácticas discursivas de la viña y el vino: algunas precisiones conceptuales}

Algunos de los conceptos que permiten sostener el análisis que se persigue en este escrito, dicen relación con definiciones y alcances que en el plano teórico se han debatido desde diferentes escuelas y aproximaciones. Acá, no obstante, se opta por aquellas que ha provisto en general la tradición francesa, y que ha sido el contrapunto analítico de este estudio. El concepto de territorio, por ejemplo, se entiende acá en la línea de lo que propone Di Méo (1991, 1998), en tanto sistema de acción y de actores, en donde la dimensión de la acción individual y la acción colectiva se tensionan y permiten articular su dimensión política, cotidiana y material, anclada tanto en normas y ordenamientos formales como en aquello que actúa en el plano de lo imaginario. Así, el territorio excede su carácter de delimitación o demarcación espacial, para extenderse al universo de acciones, significaciones y representaciones de carácter espacial, que posee respuestas y consecuencias en el plano económico, político y social. Sobre este último aspecto, trabajos como los de Porto-Gonçalves (2001) o Frémont (1995) también son complementarios.

Así, ¿a qué se quiere apuntar cuando se alude a los territorios del vino? Se busca en este sentido resaltar la condición y modo en que este atributo económico, social y cultural logra movilizar en el imaginario social que se territorializa (Aliste, Díaz y Ther, 2015) sobre cierta idea que le imprime un carácter distintivo a este territorio (Pitte, 2009; Schirmer, 2014; Frémont, 1995; Dion, 1990; Aliste \& Musset, 2014).

La noción de territorio, y, de territorios del vino como especificidad, colaborarán a dilucidar en qué medida las prácticas discursivas sobre las viñas y el vino van a producir ciertos tipos de territorios y sus respectivas tensiones. Pero, ¿qué releva o bien, a dónde lleva esta distinción de territorios del vino? ¿Qué tipo de paisaje produce y qué otro tipo de prácticas logra o puede lograr movilizar?

La idea de promover ciertos paisajes, nos lleva a lo propuesto por Berque (2008), Ingold (2000) y Nogué (2008) en el sentido de instalar una noción donde la existencia tanto física (exterior) como la humana (interior), supone una historia y una cultura que explica y permite entender 
la condición de aquello que denominamos paisaje. No está predeterminado, no es mera construcción, sino el resultado del complejo proceso histórico y social que le dé sentido y perspectiva para ponerlo en valor.

Así, podemos establecer que la noción de territorio del vino, al estar atribuida a una connotación económico productiva, pero también al intentar un sello identitario o cultural, produce una tensión que repercute en un paisaje cargado de elementos que son contradictorios, al mismo tiempo que movilizadores de un imaginario social respecto de dichos territorios. Con ello, mientras marca un carácter que distingue y entrega estatus, por esta misma razón, condiciona la producción de territorios marginados o excluidos de esta noción e identidad.

Uno de los conceptos más relevantes en esta noción que alude a los discursos del vino, es la noción francófona de terroir. Se acepta que terroir no tiene traducción literal y que se puede usar directamente, en tanto busca materializar una condición geográfica, pero en su sentido más regional que físico. Por ello es que no sólo se restringe a las condiciones de suelo, clima, geomorfología u otros atributos de la tradicionalmente denominada geografía física, sino también a su articulación con las características que tiene el modo de habitar en dichos parajes, que competen a la también tradicionalmente denominada geografía humana: tradición, saber hacer, cultura, etc.

El concepto fue propuesto en el siglo XVII por el padre de la agronomía en Francia, Olivier de Serre, pero no es sino hasta inicios del siglo XX que el término vuelve a ocuparse y esta vez, con la acepción que distingue las características que, posteriormente, permitieron definir lo que se conoce como la "Denominación de Origen" que en su acrónimo francés se denota como AOC"12 (Marre, 2009).

\section{El vino chileno, ¿Una historia entre la distinción y la exclusión social?}

La historia del vino es una oportunidad que permite un acercamiento a los conceptos propuestos por Pierre Bourdieu sobre el mundo social, relacionados con su objetivación a través del análisis de las posiciones de los actores al interior de éste. Aquello permite comprender no solo la caracterización general o estadística de actores en función de su clase, sino además reconocer la forma en que los sujetos utilizan su condición social, asociada a la forma en que se establecen las relaciones entre los grupos dentro de un campo social (Boudieu, 1999: 10). Junto con ello, al explorar conceptos como terroir, paisaje o territorio, ayuda a establecer un nexo entre las categorías clásicas en el campo del estudio sociológico con su connotación espacial, a partir de los conceptos antes enunciados. Por ello, una exploración general de corte histórico, colabora a comprender los aspectos que van perfilando el modo en el que la actividad vitivinícola ocupa un lugar, tanto en términos temporales como espaciales.

La instalación de la actividad vitivinícola en el Valle Central de Chile, permite identificar elementos que la vinculan a un campo de diferenciación social, relacionado fundamentalmente al

AOC es el acrónimo de "Appelation d'Origine Controlée" que quiere decir denominación de origen controlada. 
lugar va ocupando el vino primero dentro de las elites latifundistas chilenas, pero luego en el modo como genera nuevos sellos de distinción. La calidad del vino chileno hasta la primera mitad del siglo XIX, previo a la importación de cepas francesas, no destacaba, y, era más bien motivo de comentarios poco alentadores, la mayoría de ellos, dirigidos principalmente a la falta de prolijidad en el proceso de elaboración, que a la calidad de las cepas (Couyoumdjian, 2006). La importación de cepas francesas y la fundación de grandes viñedos va consolidando el vino como un "subproducto del auge de la elite capitalista de esos años" (Del Pozo, 1998: 63). La noción de lujo, fineza y exclusividad, asociada al imaginario francés de la época y especialmente a partir del siglo XIX, establece uno de los primeros vínculos y nociones a esta idea. No en vano se usa aún en Chile, con cierta frecuencia, la expresión popular "apellido vinoso" para referirse a aquellos apellidos que representan a la aristocracia de las familias terratenientes de Chile. Muchas de ellas de origen vasco, que por lo general bautizaban sus viñas y etiquetas con el apellido de la familia fundadora: Errázuriz, Zavala, Ochagavía, Undurraga, Urmeneta, etc. (Couyoudmjian, 2006; Vicuña, 2002). La paulatina caída en las importaciones de vinos de diferente tipo (especialmente los vinos de tipo "burdeos") y la presencia cada vez mayor de vinos nacionales en las cartas de los banquetes, van dando un lugar especial de reconocimiento a la mejora en la calidad de los vinos nacionales (Couyoudmjian, 2006), al mismo tiempo que se sitúa en las mesas de eventos y familias con el poder adquisitivo para estos efectos, donde la tradición "a la francesa" se va haciendo sinónimo local de la noción de buen gusto en las elites (Bourdieu, 2010; Bengoa, 2005; Briones, 2006). En palabras de Salazar y Pinto, en la segunda mitad del siglo XIX "avanza el afrancesamiento, los modos de vida más ostentosos y la necesidad de un cotidiano más refinado" (Salazar y Pinto, 1999: 36).

Otro elemento a considerar en la historia social de la viña, está relacionado con el vínculo que se establece entre el dueño de los viñedos y sus trabajadores, el que se caracteriza por el sistema de "inquilinaje" o "trateros", que eran obreros que vivían al interior de los fundos, recibiendo a cambio una casa, salario y ciertas regalías (Salazar, 1985; Del Pozo, 1998; Bengoa, 2005)'13, modelo que comienza a cambiar a mediados de la década de los 60 con el proceso de reforma agraria impulsado por el Presidente Frei Montalva (1964-1970), fortalecimiento la sindicalización de los trabajadores de las viñas, situación que se consolida durante el gobierno de Salvador Allende, donde se promueve la asalarización del campesinado (Del Pozo, 1998; Bengoa, 2005).

Durante la dictadura militar la industria vitivinícola se percibió a sí misma como una industria rezagada (Del Pozo, 1998), sin embargo, es durante estos mismos años que se dio inicio a una radical transformación a nivel de productores, posibilitado tanto por el marco político y social, que consolidó nuevas fortunas y nuevos grupos económicos, surgiendo nuevas asociaciones de viñateros chilenos con extranjeros dando un importante impulso al sector (Salazar y Pinto, 2002).

El auge exportador de la década de los '90 es el que caracteriza a la industria hasta la actualidad, donde el "vino pasa a simbolizar el éxito económico del país" (Del Pozo, 1998, p. 237), lo que viene asociado a un proceso de cambios tecnológicos, cambios productivos, cultivo de nuevas cepas y la incorporación de nuevos territorios del vino, como es el caso de las denominaciones Leyda y Casablanca, sólo por señalar dos icónicos cambios asociados a promover la colocación

Es importante señalar que las características del inquilino desde el siglo XVIII hasta el siglo XIX fueron cambiando drásticamente, transformándose este último en una figura muy parecida al obrero, el cual debía cumplir extensas jornadas de trabajo, y tenía muy poco terreno para poder sembrar sus propios productos (Del Pozo, 1998: 135). 
del vino chileno en el mercado extranjero. La situación de los trabajadores cambia como consecuencia de lo anterior, la tecnología trae aparejada "el ahorro" de mano de obra y como consecuencia, el menor número de trabajadores agrícolas contratados por las viñas, la erradicación, en la gran mayoría de estos fundos de los trabajadores inquilinos, lo que trajo como consecuencia un enorme transformación de "los modos de trabajo" en el espacio rural (Overton et al., 2012) y con ello, las consecuencias de exclusión de importantes sectores de la población rural, como producto indirecto de esta historia de distinción.

\section{La construcción del espacio social del vino y la producción de territorios}

El campo social circundante a la producción vitivinícola, es un elemento central para identificar las distinciones sociales surgidas en relación a la posición que asume cada uno de los actores vinculados a este sector productivo. Para efectos de este estudio se centrará la mirada específicamente en los productores del vino, trabajando tangencialmente a los consumidores y a los trabajadores del viñedo, solo en relación con la producción.

A partir de lo anterior, se centrará el análisis en los aspectos relevantes que permiten identificar los elementos de distinción que son significados al interior del campo social del vino, desde la perspectiva de la producción y consumo de este producto.

De esta forma, el territorio del vino será abordado en diálogo con los ámbitos de socialización y sociabilidad (Bordieu, 1988), dentro del cual se articulan los actores sociales en función a intereses económicos, políticos, simbólicos, además de organizarse a partir de determinados intereses.

La construcción del espacio social del vino será, por lo tanto, producto del modo de entender y dar significado a las diferentes representaciones que se hacen desde el mundo del vino y que se proyectarán en lo que hemos denominado el territorio del vino. A su vez, el territorio del vino y, por la misma razón, la emergencia de nuevos territorios que surjan desde allí, como resultado del imaginario social, será una propuesta para leer en otros códigos los procesos que se asocian a las transformaciones en la estructura social y las dinámicas recientes del espacio geográfico de los territorios del vino del Valle Central de Chile.

\section{Los discursos del vino en el Valle Central: imaginarios y particularidades de las bodegas del vino como campo social}

Para analizar los discursos de las bodegas de vinos de exportación del Valle del Central es preciso conjugar el contexto global en el que esta industria se inserta y las características particulares que asume en nuestro país. El análisis de los contenidos de sus páginas web nos proporcionará los elementos que van construyendo los imaginarios particulares de la industria vitivinícola y la influencia que éstos ejercen en los procesos de exclusión social al interior de los territorios en los que se encuentran instaladas. 


\section{Tradición y mercado}

Una de las características que asume actualmente la industria vitivinícola a escala mundial es la creciente incorporación de inversión extranjera directa asociada a intereses de capitales por productos manufacturados y con denominaciones de origen (Vargara, 2001; Chauvin, 2010). Lo que en el caso de la industria vitivinícola de exportación ha tenido una importante influencia, debido a las alianzas que se han generado entre las principales bodegas del país (Concha y Toro, Santa Rita y San Pedro, entre otras), con inversores extranjeros.

Esta situación a pesar de ser una constante en lo que respecta al actual modelo económico a escala mundial, contrasta con las características particulares de la industria vitivinícola en sus orígenes, la que se caracterizó por ser una industria de tipo familiar, que apelaba en Chile al ejercicio de dominación social que les procuraba la tierra (Del Pozo, 2004).

De este modo, el actual contexto de las bodegas de vinos chilenos denota una tensión entre inversores extranjeros y el modelo productivo familiar. La disyuntiva se sortea entre posicionarse como una industria de tradición ancestral o una industria perteneciente al nuevo mundo vitivinícola.

Con respeto a esta situación las bodegas analizadas otorgan un lugar central en sus contenidos al concepto de tradición, significando este concepto en relación a la importancia que tiene para el estatus de la bodega la trayectoria histórica de los inicios de sus procesos de vinificación. La forma de apelar a esta tradición es a partir de la relevancia que algunas bodegas le confieren a) a su origen: "Fundada en 1856, la viña Cousiño Macul es la única, entre las establecidas en el siglo $X I X$, que continúa en las manos de la familia fundadora". ${ }^{14}$; b) y, al posicionamiento del apellido de sus fundadores "En ese momento, Matías Cousiño se había consolidado como un visionario y pionero dentro de un país empezando a tomar forma en la época en que recién se había independizado de España a principios del siglo XIX"15.

El origen y el apellido familiar ologárquico, se encuentran en estrecha relación con la aspiración de acceder al prestigio "del saber hacer", desde donde se posiciona el origen de la industria vitivinícola. Lo anterior en relación a la trayectoria histórica y al estatus social que ha adquirido el apellido del dueño fundador de las bodegas (Chauvin, 2010). Transformándose este elemento en un sello de calidad y diferenciación al momento que presentarse dentro del mercado de los vinos del nuevo mundo'6.

Otro elemento a destacar en relación a la tradición familiar, es que ésta es mencionada incluso en las Viñas donde la familia original dejó de ser la propietaria, debido a la venta y paso de algunas viñas a manos de empresas multinacionales, dando cuenta que la tradición es parte de los elementos que se quieren relevar para construir el relato y narrativa del vino en el Valle Central, como parte del valor agregado: "Santa Carolina es parte de Carolina Wine Brands, uno de los prin-

\footnotetext{
Fuente: http://www.cousinomacul.com/la-empresa/

Fuente: http://www.cousinomacul.com/

La definición de nuevo mundo vitívinícola alude a la diferenciación que se realiza entre los nuevos países productores de vino principalmente fuera de los países europeos o del nuevo mundo (dentro de los cuales se encuentran principalmente Australia, Estados Unidos, Argentina y Chile); y, los productores tradicionales o del viejo continiente, países donde se originó la producción vitivinícola en occidente a los cuales se los denomina como (Francia, Italia, Portugal, España, como sus principales exponentes en la actualidad) (Villanueva, 2014).
} 
cipales grupos vitivinícolas de Chile. Actualmente pertenece al grupo agroindustrial Watt's S.A., propiedad de la familia Larraín. Con más de 135 años de historia, es una de las viñas más antiguas de Chile". ${ }^{17}$

A partir del concepto de "tradición" es posible establecer una diferenciación entre los tipos de viñas instaladas en el Valle Central. Por un lado, las bodegas asociadas a familias con "apellidos vinosos" $y$, por otro, las bodegas de pequeños propietarios que dan cuenta de la importancia del "negocio familiar", como un elemento diferenciador en la producción de vinos de calidad. Dentro de este contexto, familia y territorio se asocian, por un lado, enfatizando en la producción sustentable, y, por otro, aludiendo a los vínculos que ha tenido la familia con el lugar en el que habitan: Antiyal, una pequeña bodega de una hectárea en la zona de Huelquen nace el año 1996 de la mano de Álvaro Espinoza y su familia, Con la idea de producir buenos vinos a pequeña escala y con un manejo orgánico de sus viñedos que hoy también practica la agricultura biodinámica". ${ }^{18}$

\section{Status y distinción: en relación a los vínculos de las bodegas con los productores del viejo mundo}

La alusión al vínculo existente entre productores del "viejo mundo" especialmente de origen francés, es otro de los elementos que caracteriza al campo social del vino en Chile, otorgándole una centralidad en el relato al vínculo que estas bodegas tienen con antepasados migrantes europeos. Resaltando la importancia que le confiere esta industria al savoir faire, o la experiencia en el trabajo con las viñas (técnicas de vinificación y trabajo en el campo), lo que les daría un sello de calidad por tradición. Situación que no tiene un vínculo directo con los modos de producción que desarrolla la gran industria vinícola chilena en la actualidad, cada vez más tecnologizada y automatizada.

En los contenidos de las páginas web es posible distinguir discursos que enfatizan en: a) la relación entre el apellido familiar y la trayectoria productiva del vino: "La familia Antinori está en el negocio vitivinícola desde el año 1385, con 26 generaciones en el rubro y 1700 hectáreas repartidas por Europa. Sus más de 600 años de historia lo posicionan como una de las empresas con más experiencia y calidad a nivel mundial" ${ }^{19}$; b) La historia de la viña vinculada con un pasado aristocrático o ligado a antepasados europeos migrantes en tierras chilenas, principalmente franceses, además de españoles y portugueses: “La historia de Viña El Principal comienza a principios de los años 90, cuando Jean Paul Valette - el reconocido productor francés de vinos y ex dueño del famoso 1st Grand Cru Classé Chateau Pavie en Saint-Émilion- se propuso producir uno de los mejores vinos tintos del Nuevo Mundo. ${ }^{20}$; c) y la alusión directa al vino francés, refiriéndose a la forma en que expertos franceses han impactado en la producción del vino chileno: "Arnaud es nuestro enólogo francés, nació y estudió en Bordeaux. Pasó sus tres primeros años como enólogo profesional recorriendo las principales regiones vitivinícolas del mundo (Sudáfrica, Hungría, California, Argentina y Francia). También trabajó como enólogo y encargado de ventas para una renombrada empresa tonelera en Francia" ${ }^{\prime 2}$.

\footnotetext{
Fuente: http://www.santacarolina.cl/cl/quienes-somos/

Fuente: http://www.antiyal.com/chile/antiyal-kuyen/

Fuente: http://www.harasdepirque.com/vina/sociedad

Fuente: http://www.elprincipal.cl/

Fuente: http://odfjellvineyards.cl/es/equipo/arnaud-hereu/
} 
Llama la atención que cada vez que se hace referencia a Francia, es para vincularlos con los vinos más exclusivos que cada holding o viña familiar produce. En 1997, La Baronesa Philippine de Rothschild, Presidente del Directorio Asesor de Baron Philippe de Rothschild S.A., y Don Eduardo Guilisasti Tagle, Presidente de Viña Concha y Toro S.A., cerraron un acuerdo en sociedad con la visión de crear un vino Premium Franco-Chileno excepcional, llamado Almaviva.Producido bajo la supervisión técnica en conjunto de ambos socios, la primera cosecha fue de inmediato un suceso internacional luego de su lanzamiento al mercado en 1998".22

\section{Terroir}

Dentro de la agroindustria de exportación asociada a la elaboración de productos con denominación de origen, cobra cada vez más significancia el terroir, concepto que se define en función a las características que le otorga el lugar - territorio donde se origina la producción. La definición de terroir, desde la perspectiva etimológica está vinculada con la palabra proveniente del latín "territorium", la cual en su contenido denota un vínculo estrecho con el sentido geográfico que otorga la tierra a los productos que emanan de él (Duhart, 2011). El uso del concepto de terroir se encuentra asociado a una diversidad de perspectivas en su utilización que van desde enfoques naturalistas, utilizados por la agronomía y las ciencias de la tierra; o por enfoques humanistas asociados a la geografía humana, historiadores y ruralistas, usándolos para describir "los procesos por los cuales las sociedades "conquistaron", labraron y gestionaron los espacios agrícolas que las rodeaban". Para ellos, el terroir era, antes que nada, un territorio apropiado por un grupo humano" (Duhart, 2011).

Sin embargo, en la práctica los enfoques naturalistas y humanistas han tendido a converger surgiendo una tercera línea de acercamiento a esta realidad de tipo relacional. Que sintetiza la definición de terroir como "lugares de interacción eco - culturales por esencia" (Duhart, 2011).

Es por esta razón que no es de extrañar la centralidad que adquiere en los discursos de las bodegas la mención recurrente del terroir. Concepto que al igual que su definición, trae asociada una diversidad de interpretaciones, relacionados con los elementos que cada una de las bodegas considera importantes de relevar: a) los aspectos asociado a las características geográficas generales del paisaje, la naturaleza y el entorno en el que se encuentran instaladas los parronales y la bodega: "Pure water irrigates the valleys, the sun moves delicately across the vineyards which grow in a harmonic setting of light, temperature, and fertility: the "terroir" a term which the French use to denominate the environment in which each type of grape develops". ${ }^{23} ; b$ ) aspectos distintivos del territorio, haciendo alusión explícita y a través de las imágenes a la importancia que tiene la producción de vino en relación a la Cordillera de los Andes: "El área vitícola del Alto Maipo -donde se encuentran los viñedos de Cousiño Macul- está ubicada en el sector Sur Este de la cuenca del Río Maipo, en el área más cercana a los faldeos de los cerros de la Cordillera de los Andes. Su cercanía a la Cordillera hace que el valle se beneficie con el "efecto Andes", que se refiere al aire fresco que desciende de las cumbres en las tardes, disminuyendo las temperaturas y estableciendo una mayor amplitud térmica"24.

\footnotetext{
Fuente: http://www.almavivawinery.com/html/espanol/historia1.html

Fuente: http://www.frui.be/ProductLeverancierSubFR.asp?LevCode=SA\&Print=Print

Fuente: http://www.cousinomacul.com/vinedos/alto-maipo/
} 
A partir del concepto de terroir es posible reconocer los elementos que se perciben como relevantes para dar cuenta de la producción del vino. En general se trata de una definición más bien estática, relacionada con aspectos culturales y características del suelo, que le confieren particularidades a cada uno de los vinos, abordándose sólo tangencialmente el tema del manejo y el valor agregado que se le puede otorgar a una definición de terroir multidimensional, tal como se aludió a la definición de este concepto.

Cabe mencionar, de todos modos, que por más que se recurra a las características de aquella geografía física que permite definir el terroir, el que necesariamente se vincule a aspectos culturales o humanos es lo que hace que este concepto en Chile aun sea una debilidad esencial del concepto en sí y su uso.

\section{Medio ambiente}

Otro concepto recurrente identificado en el discurso de las viñas, es su relación con el medio ambiente, aludiendo principalmente a una definición asociada a las exigencias impuestas por los principales mercados en donde el vino chileno se posiciona.

Sólo en ciertas ocasiones, muy poco frecuentes, se hace alusión a la relación de medio ambiente y comunidad local. Esto es muy relevante debido a que, a pesar de lo poco mencionada, es una de las únicas instancias en donde las viñas hacen referencia a los vínculos con el territorio donde estás se encuentran instaladas. Sin embargo, el modo de entender la relación con la comunidad permite aún una amplia discusión, pues ésta se remite, al menos en el caso aquí revisado, a un apoyo de tipo paternalista, pero muy distante aun de iniciativas que promuevan conceptos como por ejemplo, el de valor compartido: "Un Compromiso con la naturaleza y nuestro entorno" [...]han incluido la gestión integrada de los cultivos, programas de reforestación, tratamiento de residuos de última generación y reciclaje, el reemplazo de motores, luminaria, alternadores y otros elementos por aparatos eficientes que ahorran energía, así como el cultivo orgánico de un creciente porcentaje de sus viñedos. "Buenos vecinos para quienes nos rodean" [...] Algunas de nuestras iniciativas hacia la comunidad son: "Compartiendo con un Amigo:" campañas: "Útiles escolares", "Compartir en Navidad" y "El Kilo de la Solidaridad", que consiste en la recolección de alimentos no perecibles. "Fútbol" [...] ha desarrollado una boyante escuela de fútbol, que hoy en día ya incluye dos estadios comunitarios. [...] "Educación para la familia": [...]por ello creó un programa diseñado para orientar a los padres en cuanto a la educación de sus hijos respecto del consumo responsable de alcohol. "Consuma con Responsabilidad": incluimos advertencias en nuestras etiquetas y material promocional" ${ }^{\prime 25}$.

Así, la relación de las viñas con los aspectos asociados a las comunidades en las que encuentran instaladas sus bodegas, queda circunscrita a aspectos relacionados más bien con la responsabilidad social empresarial, dando en todo momento un sello más apegado a la dimensión de negocio internacional. Pero su vínculo con aspectos asociados al "campesinado tradicional chileno", o bien, al habitante que vive el territorio donde estos vinos ven su origen, es prácticamente inexistente. Esto se puede deber a que los vinos que se producen en éste tipo de bodegas están orientados principalmente a la exportación, por lo que los imaginarios que se construyen en relación al territorio son más bien genéricos:

\footnotetext{
25 Fuente: http://www.sanpedro.cl/sustainability-medioambiente/. Negritas de la página web.
} 
“La Viña y Haras de Pirque cree firmemente en la importancia de la Sustentabilidad como política empresarial, en los ámbitos relacionados con el medio ambiente, con la responsabilidad social y con la dimensión económico-financiera. Para esto hemos desarrollado distintos proyectos que apuntan a realizar una actividad productiva sustentable y responsable dentro de nuestra comunidad, tales como el manejo de viñedos en agricultura orgánica, la medición de nuestra huella de carbono y programas de eficiencia energética. Así también, incentivando la capacitación y desarrollo profesional de nuestros trabajadores, siendo para nosotros primordial los esfuerzos realizados en el área de seguridad laboral" 26 .

La desterritorialización es otra de las características que es posible identificar en el contenido de las bodegas del Valle Central. Comprendiendo a la desterritorialización como parte de las propiedades características del capitalismo, extremándose en el actual modelo capitalista, donde "las prácticas y las estrategias de estos actores sociales son fuertemente globalizados y aparentemente desprendidos de los territorios donde transitan" (Hiernaux y Lindón, 2004).

La forma en que se evidencia esta desterritorialización es a partir del proceso en el cual las prácticas sociales y productivas se encuentran disociados con respecto al lugar donde se concretan los negocios de las principales bodegas del Valle Central. Esto debido a que sus direcciones de contacto hacen alusión a comunas en donde se encuentran instaladas las oficinas centrales de las grandes empresas del país: Las Condes, Vitacura y Providencia.

Situaciones que pone en evidencia la relación dicotómica que existe entre las bodegas y el territorio, debido a que por un lado la referencia al terroir alude a la centralidad que tiene para las viñas las características específicas en los que se encuentran sus viñedos y, por otro lado, la relevancia que tiene para esta industria el posicionamiento como negocio en el centro neurálgico donde se producen las inversiones e intercambios bursátiles a escala global. Un ejemplo de la condición desterritorializada de las viñas es lo ocurrido durante la huelga sostenida por los trabajadores de la viña Concha y Toro el año 2013, donde las demandas de los trabajadores llegaron hasta las oficinas instaladas en la comuna de Las Condes, debido a las dificultades de negociación que tuvieron en la primera etapa en las que solo se hicieron presente en las inmediaciones de la bodega.

\section{Vínculo con el trabajador: una relación invisibilizada}

La relación que estas empresas establecen con los trabajadores en su discurso es más bien una relación invisibilizada, haciendo referencia, por lo general, al equipo de profesionales que trabaja en la viña; la excepción emerge cuando median instancias de certificación o bien, páginas que incorporan la noción de sustentabilidad (ver Figura $N^{\circ} 1$ ), donde esta dimensión lleva rostro. También surgen las imágenes y alusiones en vinos de gran calidad cuando estos son cosechados manualmente. "En tiempo de vendimia, estos diferentes cuarteles son cosechados separadamente y en épocas diferentes. Incluso secciones de una misma hilera individual pueden ser cosechadas en dos o tres oportunidades. Sólo las mejores uvas son seleccionadas, y todas son cosechadas a mano. Luego son transportadas a la planta utilizando bandejas de $16 \mathrm{Kg}$. para garantizar que la fruta sea recibida en óptimas condiciones" ${ }^{27}$.

Fuente: http://www.harasdepirque.com/haras/sustentabilidad

Fuente: http://www.vinedochadwick.cl/es/vi\%C3\%B1edo-chadwick 
Figura $\mathrm{N}^{\circ} 1$

Imagen de trabajadores Viña San Pedro
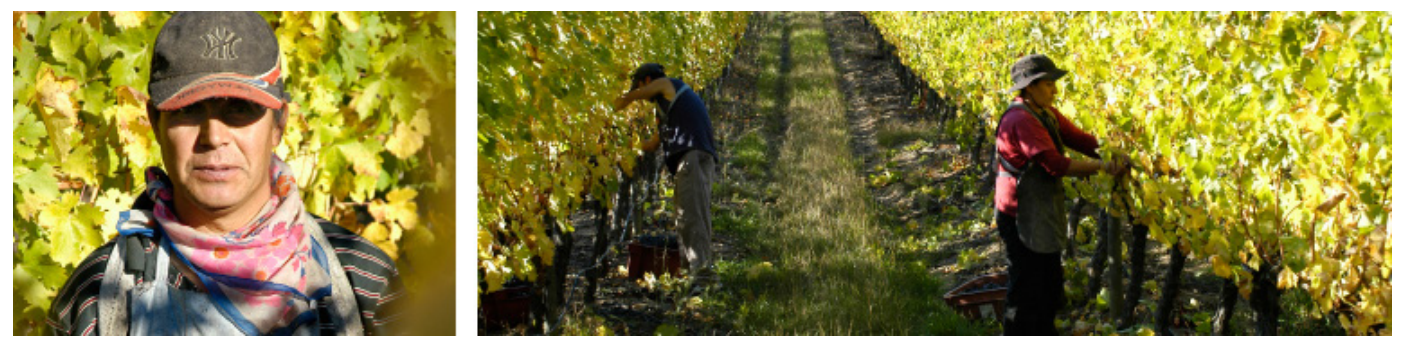

Fuente: http://www.sanpedro.cl/sustainability-medioambiente/

\section{La producción de vino de exportación como referente de exclusividad y distinción social}

Finalmente, un último aspecto que destaca en los imaginarios y representaciones contenidos en el mundo del vino, están relacionados con la idea de exclusividad, de estar a la moda, marcando tendencia y una estética muy propia de un mundo urbano que consume, bastante lejos de los territorios en que se producen los vinos (ver Figura $N^{\circ} 2$ ). La salvedad emerge cuando surge una situación puntual de amenaza, que estuvo presente en momentos en que se discutía en Chile la reforma tributaria de 2014; en dicho contexto, el mundo del vino toma el rostro de un trabajador (ver Figura $\mathrm{N}^{\circ} 3$ ).

Figura $\mathrm{N}^{\circ} 2$

Imágenes de la campaña nos gusta el vino, de Vinos de Chile

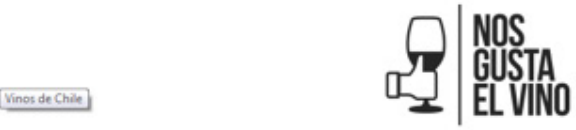

Luganes mosica antervino La ouevino? couevino levo? cata

Vinos de Chile.

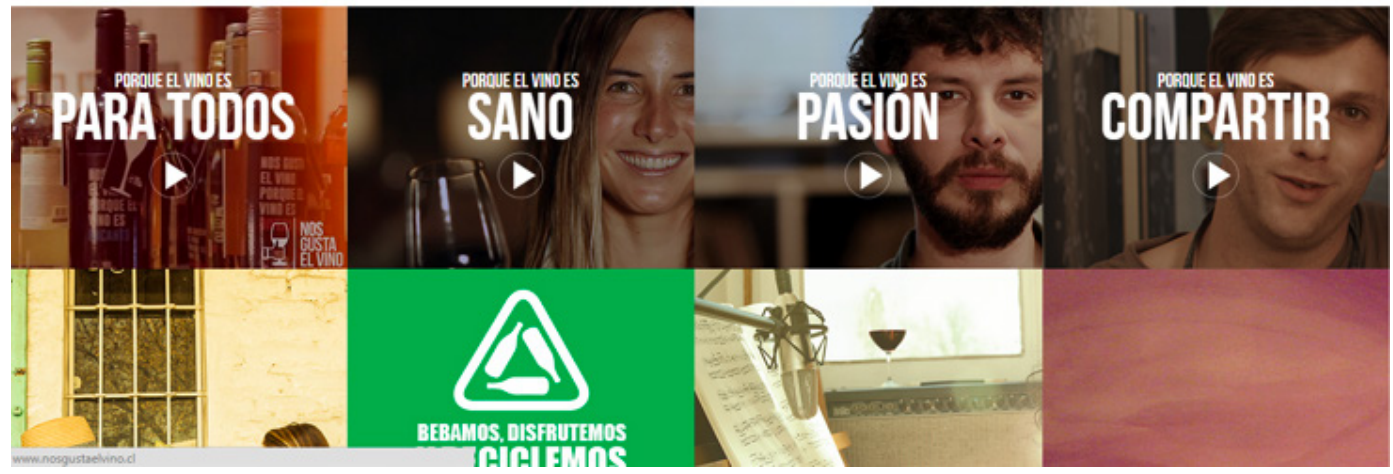

Fuente: http://www.nosgustaelvino.cl 
Figura $\mathrm{N}^{\circ} 3$

Imagen de la campaña nos gusta el vino, de Vinos de Chile, en el marco de la discusión del proyecto de reforma tributaria 2014 (difundido ampliamente por la prensa escrita)

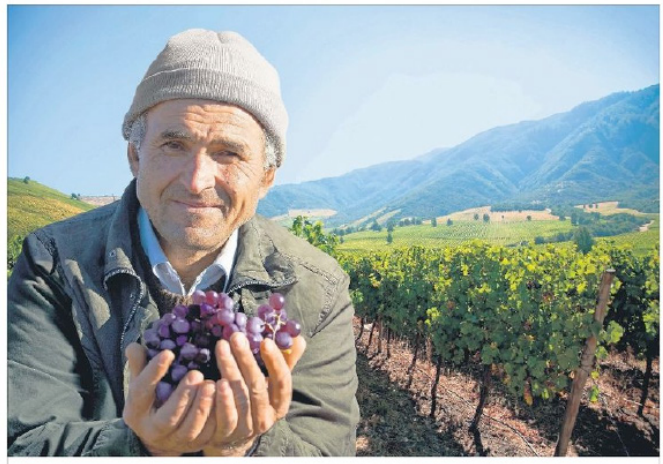

NOS GUSTA

EL VINO

PORQUE ELVINOES

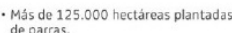

- Más de 100.000 personas trabajan

- El 85\% del empleo vitivinicola esta en TRABAJO

PROTEJAMOS NUESTRO PATRIMONIO
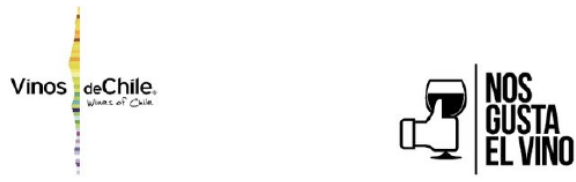

Fuente: http://www.nosgustaelvino.cl

\section{Conclusiones}

A partir del análisis de los discursos de las viñas y el mundo del vino, es posible identificar ciertos elementos que otorgan al territorio del Valle Central un sello, una característica y un modo de representación que permite conformar e identificar un imaginario particular que impregna los territorios del vino en Chile. Lo anterior asociado a definiciones globales con implicancias locales, que dan cuenta de la relevancia que adquiere el discurso de las viñas como productor de un imaginario de territorios del vino exclusivo y a su vez excluyente.

En primer lugar, está la idea de una actividad que pretende ser definida como una industria tradicional y con una larga historia en la producción del vino, aludiendo a apellidos de la aristocracia chilena, a migrantes de territorios reconocidos como los pioneros en su producción, principal- 
mente provenientes de Francia, a instalar una noción vinculada a la elegancia, el refinamiento y aspectos que se asocian a un modo de vida exclusivo que, a la vez, es muy excluyente.

Sin embargo, a pesar de lo anterior, el discurso entregado por las viñas es más bien hegemónico de la industria vitivinícola global, asociado principalmente a la vocación exportadora de esta industria. Un ejemplo de lo anterior es el discurso enunciado con respecto al medio ambiente, el cual no se define desde la relación entre el medio ambiente y el territorio, sino más bien en relación a las exigencias que impone el mercado internacional. No se considera en la mayor parte de los casos, los efectos ambientales en los territorios donde están instaladas, aludiendo solo a las certificaciones ambientales adquiridas, ciertas prácticas anexas a la actividad y algunas acciones de apoyo a grandes cruzadas.

En relación a los campos sociales en los que se mueve esta industria, éstos se encuentran vinculados a los intereses económicos de éstas, los que evidentemente apuntan al mercado internacional, el cual incide directamente en la escasa importancia que las bodegas les otorgan a los espacios locales. Sus referencias a vínculos con la comunidad, están más bien asociados a procesos de responsabilidad social empresarial, de tipo paternalista, y enfocados en muchos casos a acciones de asistencialismo, existiendo en casos muy particulares un real interés por dinamizar el desarrollo de los espacios locales en los que se encuentran instaladas. De ello se interpreta que lo que las moviliza a explicitar este vínculo, es más bien un gesto simbólico en relación a las expectativas que puede tener el consumidor global con respecto a un producto a consumir. Por ello, es posible señalar que el territorio que se representa en el discurso de los vinos del Valle Central, en general, no tiene relación con las prácticas sociales y la cotidianeidad vivida al interior de éstos, salvo en ocasiones puntuales donde el tema adquiere una dimensión folclórica.

Es muy relevante destacar el lugar privilegiado que el origen social de los propietarios representa para efectos de establecer y movilizar un imaginario sobre la noción de buen gusto, elegancia, posición social y rol que la producción de vino instala desde estas formas de representación, para impregnarlo en los territorios en que se desarrolla la actividad. Sin embargo, al mismo tiempo que sucede este fenómeno, también se sabe de la prácticamente total invisibilización del habitante, de los saberes locales, de la relación entre viñas y comunidad local. Sin embargo y pese a ello, se usa ampliamente el concepto terroir, identificándolo exclusivamente con atributos físico-naturales, pero no con el saber local.

En resumen, es posible inferir que los imaginarios que resultan de los discursos de la viña y el vino, dan origen a un territorio imaginado que se distancia de las condiciones locales, pero al mismo tiempo logra un efecto de dinamización propia de los territorios del vino. Tal como se pudo apreciar, los importantes incrementos de la actividad, tanto en superficie, producción e ingresos, contrastan con una inexistente alusión a un modo de vida campesino que, probablemente por estas mismas acciones, colaboran a su paulatina desaparición.

\section{Referencias bibliográficas}

ALISTE, E.; DÍAZ, A. y THER, F. Transformaciones territoriales y discursos del desarrollo en el Gran Concepción (Chile), 1960-2010. Aproximaciones desde la perspectiva de los imaginarios al estudio de la valoración ambiental del territorio. Atenea, 2015, N512, p. 49-67. 
ALISTE, E. y MUSSET, A. Pensar los territorios del desarrollo: sustentabilidad y acción pública en nombre de una ciudad imaginaria. Concepción (Chile), 1950-2010. EURE, 2014, Vol. 40, No 120, p. 91-110.

ASSELOT, P. El paisaje del vino. ARQ, 2003, № 54, p. 56-61.

BENGOA, J. La comunidad reclamada. Identidades, utopías y memorias en la sociedad chilena actual. Santiago de Chile: Catalonia, 2005.

BENGOA, J. Valle Central. Memorias, patrimonio y terremoto en haciendas y pueblos del Chile Central. Editorial Catalonia, 2012.

BERIAIN, J. Las consecuencias perversas de la modernidad: modernidad, contingencia y riesgo. Barcelona: Anthropos, 1996.

BERQUE, A. La pensée paysagère. Paris: Archibooks, 2008.

BLANCO, C.; ANDRADE, L. y MONTERO, A. Bodega Santa Ema. ARQ, 2003, № 54, p. 38-43.

BOURDIEU, P. El sentido social del gusto. Elementos para una sociología de la cultura. Buenos Aires: Siglo XXI Editores, 2010.

BOURDIEU, P. Contrafuegos. Reflexiones para servir a la resistencia contra la invasión liberal. Barcelona: Anagrama, 1999.

BOURDIEU, P. La distinción. Criterio y bases sociales del gusto. Madrid: Taurus, 1988.

BRAVO, N. En el borde de la copa: Literatura e identidad chilena en torno al vino. Santiago de Chile: Licenciatura en Lengua y Literatura Hispánica con mención en Literatura Hispánica, Universidad de Chile, 2008.

BRIONES, F. Los inmigrantes franceses y la viticultura en Chile: El caso de René F. Le Feuvre. Universum, 2006, Vol. 21, № 2, p. 126-136.

BUSTOS, B. Brote del virus ISA: crisis ambiental y capacidad de la institucionalidad ambiental para manejar el conflicto. EURE, 2012, Vol. 38, N 115, p. 219-245.

BUZZETTI, C. Boletín del vino: producción, precios y comercio exterior. Avances a diciembre de 2017. Santiago de Chile: Publicación de la Oficina de Estudios y Políticas Agrarias (Adepa) del Ministerio de Agricultura, Gobierno de Chile, 2018.

CASTEL, R. Las metamorfosis de la cuestión social. Una crónica del salariado. Buenos Aires: Paidós, 1997.

CHARTIER, R. El mundo como representación. Estudios sobre historia cultural. Barcelona: Gedisa, 2005. 
CHAUVIN, P. Le marché des reputations. Une sociologie du monde des grands crus de Bordeaux. Bordeaux: Éditions Féret, 2010.

CHAZARRETA, A. Capital extranjero y agroindustria : Notas para una discusión sobre los cambios en la burguesía vitivinícola de Argentina a partir de la década del '90. Mundo Agrario, 2013, Vol. 13, N 26. Disponible en Internet: http://www.memoria.fahce.unlp.edu.ar/art_revistas/pr.5692/ pr.5692.pdf

COURARD, P. (2003). Sala de degustación. ARQ, 2003, N 54, p. 34-35.

COUYOUMDJIAN, J.R. Vinos en Chile desde la independencia hasta el fin de la belle époque. Historia, 2006, Vol. 39, N¹, p. 23-64.

CRUZ, J. \& TURELL, A. Bodegas en Los Robles. ARQ, 2003, N 54, p. 20-27.

DEL POZO, J. Historia del vino chileno. Santiago de Chile: Editorial Universitaria, 1998.

DI MEO, G. L'homme, la société, l'espace. Paris: Anthropos, 1991.

DI MEO, G. Géographie sociale et territoire. Paris : Nathan Université, 1998.

DION, R. Le paysage et la vigne. Essais de géographie historique. Paris : Éditions Payot, 1990.

DUHART, F. Reflexiones desde la eco - antropología sobre el terroir. Mundo Agrario, 2011, Vol. 11, $N^{\circ} 22$.

FOUCAULT, M. La arqueología del saber. Buenos Aires: Siglo XXI Editores, 2002.

FOUCAULT, M. L'ordre du discours. Paris: Gallimard, 1971.

FREMONT, A. Les profondeurs des paysages géographiques. En : Roger, A. (editor). La théorie du paysage en France (1974 - 1994). Seyssel: Champ Vallon, 1995, p. 21-41.

GAC, D. Modos de inclusión / exclusión social en los territorios del Vino Chileno: los impactos sociales de la reconversión productiva en el Valle de Colchagua. Santiago de Chile: Tesis para optar al Grado de Doctora en Ciencias Sociales, Facultad de Ciencias Sociales, Universidad de Chile, 2017.

GIDDENS, A. Consecuencias de la modernidad. Madrid: Alianza Editorial, 1993.

INGOLD, T. The perception of the environment: essays on livelihood, dwelling and skill. London: Routledge, 2000.

KRIPPENDORFF, K. Metodología de análisis de contenido. Teoría y práctica. Barcelona: Paidós, 1990. 
LACOSTE, P. El vino y la nueva identidad de Chile. Universum, 2005, N²0, p. 24-33.

LARRAÍN, J. Identidad chilena. Santiago de Chile: LOM Ediciones, 2001.

MARRE, A. Le désir du vin à la conquête du monde, Jean-Robert Pitte. Physio-Géo, 2009, Vol. 3, $N^{\circ} 1$, p. 11-12.

MONDREGO, F. Dinámicas territoriales del Secano Interior de la Región de O'Higgins: Las fronteras de la transformación agroindustrial. Santiago de Chile: RIMISP, Documento de trabajo Nº 80, 2011.

NOGUÉ, J. El Paisaje en la cultura contemporánea. Madrid: Biblioteca Nueva, 2008.

OFICINA DE ESTUDIOS Y POLÍTICAS AGRARIAS (ODEPA). El sector vitivinícola nacional: una visualización de la situación mundial, la estructura productiva y la evolución de las exportaciones. Santiago de Chile: Oficina de Estudios y Políticas Agrarias, Documento de trabajo en Línea. 2015.

OFICINA DE ESTUDIOS Y POLÍTICAS AGRARIAS (ODEPA). Panorama de la agricultura chilena / Chilean agriculture overview. Santiago de Chile: Ministerio de Agricultura, 2012.

ORGANIZACIÓN INTERNACIONAL DE LA VIÑA Y EL VINO (OIV). Statistical Report on World Vitiviniculture 2012. Paris: Statistics Department, International Organisation of Vine and Wine, 2012.

OVERTON, J.; MURRAY, W. \& PINO, F. The remaking of Casablanca: the sources and impacts of rapid local transformation in Chile's wine industry. Journal of Wine Research, 2012, Vol. 23, № 1, p. 47-59.

PITTE, J-R. Le désir du vin. A la conquête du monde. Paris: Fayard, 2009.

ROBLES, F. El desaliento inesperado de la modernidad. Molestias, irritaciones y oportunidades de la sociedad del riesgo. Santiago de Chile: RIL Editores, 2000.

SÁEZ, C.; JOANNON, X. y LÓPEZ, J.I. Bodega Los Maquis. ARQ, 2003, № 54, p. 28-34.

SERVICIO AGRÍCOLA GANADERO (SAG). Catastro Vitícola Nacional, 2005 - 2015. Santiago de Chile: Servicio Agrícola Ganadero, 2015.

SALAZAR, G. \& PINTO, J. Historia contemporánea de Chile II. Actores, identidad y movimiento. Santiago de Chile: LOM Ediciones, 1999.

SALAZAR, G. \& PINTO, J. Historia contemporánea de Chile III. La economía: mercados, empresarios y trabajadores. Santiago de Chile: LOM Ediciones, 2002.

SALAZAR, G. Peones, labradores y proletarios. Formación y crisis de la sociedad popular chilena del siglo XIX. Santiago de Chile: Ediciones SUR, 1985. 
SCHIRMER, R.; ALISTE, E.; BUSTOS, B.; GAC, D.; GOLDSTEIN, N. \& ROUVELLAC, E. Vignobles et vins du Chili : un nouveau monde viti-vinicole révolutionnant la promotion et la valorisation du vin ? HAL archives-ouvertes.fr. 2013. Disponible en Internet :

https://hal.archives-ouvertes.fr/hal-00862754.

SCHIRMER, R. Holly[wine] ou le vin dans le cinéma américain. Annales de Géographie, 2014, № 697, p. 867-889.

TIJOUX-MERINO, M.E. Niños(as) marcados por la inmigración peruana: estigma, sufrimientos, resistencias. Convergencia, 2013, Vol. 20, N61, p. 83-104.

TOURAINE, A. ¿Podremos vivir juntos? México DF.: Fondo de Cultura Económica, 1997.

VERGARA, S. El mercado vitivinícola mundial y el flujo de inversión extranjera a Chile. Santiago de Chile: CEPAL, Serie desarrollo productivo Vol. 102, 2001.

VINOS DE CHILE. Memoria anual. Santiago de Chile: Vinos de Chile, 2016.

VINOS DE CHILE. Informe Ejecutivo: "Estudio de inteligencia de mercado laboral para la industria vitivinícola". Santiago de Chile: Fundación Chile, 2014.

VILLANUEVA, E. La innovación como causa del éxito exportador vinícola del Nuevo Mundo Anglosajón. Revista Iberoamericana de Viticultura, Agroindustria y Ruralidad, 2014, Vol. 1, № 1, p. 1-13.

VISSER, E.-J. \& LANGEN, P.D. The importance and quality of governance in the Chilean wine industry. Geojournal, 2006, Nº5, p. 177-197. 